\title{
CORRESPONDENCE
}

To the Editor of the A eronautical Journal.

\section{LAWS OF AFROIDYNAMICS AND LANGLEY'S LAW}

SiR,-May I be allowed to comment on Mr. Turnbull's very interesting article in the Afronautical. Journal of January? My desire is to point out in what way Mr. 'Turnbull's inferences from Langley's and M. Eiffel's experiments may be extended so as to cover more ground, and be brought into collaboration, in a manner of speaking, with the results of investigations which have proceeded on other lines. In doing this, I hope to add to the usefulness of Mr. Turnbull's work, since it is obvious that the more cases can be included under a certain law, the more useful does the law become in design as well as in practice. Regarding Law A, it is, mutatis mutandis, nearly Rankine's old doctrine of screw propellers generalized. Law B stands on a somewhat different footing, as it forms a complement to Langley's law, or paradox, whichever it is to be called. In quoting authorities hereinafter I do so from memory, without regard to priority or exhaustiveness, for I am at present away from books, so cannot verify my references and I clainn no originality.

With regard to Law 3 , which concerns maximum load for carrying power per horsepower, lanchester, for instance, discusses Langley's law, and, after pointing out that it (an only be true of perfectly thin---I fear thicknessless is not an English word-and frictionless planes, he finds that, taking account of direct head resistance due to surface friction and framing, \&c., there are two notable speeds of any given machine, with given area and load -one, the higher, at which the total resistance is a minimum ; the other, at which the horsepower to carry the load is a minimum. The latter is the same thing as Mr. Turnbull's speed for maximum load per horsepower. The mathematics are simple enough on the assumptions, firstly, that head and frictional resistances vary as the square of the speed, and secondly, that their sources may be represented for purposes of calculation, by a plane of fixed area, square to the wind, the supporting or main plane boing treated as frictionless and thin. Neither of these assumptions is in exact agreement with facts, no doubt, but it will hereinafter appear that for most purposes, the agreement is sufficiently near to be useful. There is no difficulty, and I need not trouble you with the formal proof, in showing that, on the above assumptions, if we put load carried per horsepower $=1$; square feet of wing area per 1000 lbs. or other unit load $=\mathrm{s}$; speed $=\mathrm{V}$, and if $\mathrm{V}$ be the speed for which load carried per horsepower is a maximum, then in Figs. 2, 3, 4, 5, 6, and 7 of Mr. Turnbull's article, the curves in Figs. 2, 4, and 6 are common hyperbola, in which $\mathrm{IV}=\mathrm{I}$, a constant; and in Figs. 3, 5, and 7, the curve which starts from the origin is a common parabola, $\mathbf{l}^{2}=\mathrm{Ms}$ where $\mathrm{M}$ is a constant ; and the other curve is a kind of hyperbola in which $\mathrm{sV}^{2}=\mathrm{N}$, a constant also. The constants will, of course, differ in the three sets of experiments, owing to the planes 'xperimented on differing from one another in various ways, and will, like most engineers' " constants," vary a bit from point to point along the curves." On testing the figures arithmetically, the constants turn out to be quite good constants, considering the generally notorious bad character of hydrodynamical constants, particularly those connected with the propulsion, \&.e., of ships, to which these are nearly akin.

The numerical values of the "constants" taken from the curves as printed in Mr. 'Turnbull's article are as follows-minute accuracy being neglected :-

\begin{tabular}{|c|c|c|c|c|c|}
\hline Fig. & $\mathrm{IV}=\mathrm{L}$ & Fig. & $1^{2}=\mathrm{Ms}$ & $\mathrm{sV}^{2}=\mathrm{N}$ & \\
\hline 2\{ & $\begin{array}{l}78 \times 32=2500 \\
60 \times 43=2600 \\
33 \times 73=2410\end{array}$ & 35 & $\begin{array}{l}33^{2}=5 \cdot 44 \times 200 \\
48^{2}=5 \cdot 76 \times 400 \\
74^{2}=6 \cdot 08 \times 900\end{array}$ & $\left.\begin{array}{l}216 \times 70^{2}=1060 \\
425 \times 50^{2}=1060 \\
900 \times 35^{2}=1040\end{array}\right\}$ & $\times 1000$ \\
\hline 4 & $\begin{array}{l}77 \times 26=2000 \\
63 \times 32=2000 \\
57 \times 37=2100\end{array}$ & 53 & $\begin{array}{l}37^{2}=6 \cdot 82 \times 200 \\
52^{2}=6 \cdot 76 \times 400 \\
70^{2}=6 \cdot 13 \times 800\end{array}$ & $\begin{array}{r}200 \times 57^{2}=650 \\
400 \times 40^{2}=640 \\
1000 \times 25^{2}=625\end{array}$ & $\times 1000$ \\
\hline 6 & $\begin{array}{r}228 \times 22=5020 \\
163 \times 31=5050 \\
125 \times 42=5250 \\
93 \times 56=5200\end{array}$ & 7 & $\begin{aligned} 97^{2} & =47 \times 200 \\
148^{2} & =55 \times 400 \\
180^{2} & =54 \times 600 \\
220^{2} & =54 \times 900\end{aligned}$ & $\begin{array}{r}200 \times 53^{2}=560 \\
500 \times 31^{2}=480 \\
800 \times 24^{2}=460 \\
1000 \times 21^{2}=440\end{array}$ & $\times 1000$ \\
\hline
\end{tabular}


These figures show that the reason the experiments ho eites give the results as to speed, area, and maximum load per horsepower which Mr. Turnbull extracts from them, is just very nearly that which has formed the basis for the approximate equations of the curves. In other words, Law B is the consequence of the existence of direct resistance, nearly resembling that of a plane of constant area, facing the wind, attached to a supporting plane having no thickness or friction, which would, by itself, follow Langley's law. Langley himself assigned as a reason for the curve $\mathrm{A}$ of his experiments (see $\mathrm{Mr}$. 'Turnbull's Fig. 1) being what it is, the thickness and square edge of the experimental plane, which at small angles of attack constituted a resistance plane of sensible area, and he corrected the curve A accordingly. We need not then hesitate to oxtend the application of the explanation of Law B above given, to other cases, and in particular to the case of minimum resistance.

The speed of minimum horsepower for a given load, otherwise the speed of maximum load for that horsepower, would, I believe, be found to be in practice very inconvenient and perhaps dangerous, because any casual disturbance of that speed, whether it be increase or decrease, calls for increase of horsepower to correct it. The speed of minimum resistance has the advantage that casual disturliance of the speed, if small, scarcely alters tho resistance at all, and if considerable, it reduces the horsepower necessary for support if it reduces the speed, because the speed of mininum horsepower is less than that of minimum resistance, and if it increase the speed, the engine thrust usually diminishes, so that the disturbance tends, in a manner, to correct itself; and there is a good margin for loss of power from accidental causes, such as missed ignitions, \&c., to fall back on before the minimum horsepower limit is reached. I suppose, indeed, that for very sufficient reasons regarding safety and controllability, aviators would, intentionally or unintentionally, arrive at flying small or medium power machines at speeds lying between that of mininum horsepower for their lower, and of minimum resistance for their upper, limit. The rango of speed is about 30 per cent. of its lower limit, and the range of power about 15 por cent. of the same.

High pover machines may, of course, be made to fly at speeds exceoding that of minimum resistance, but if they do, it is at the sacrifice of total distance or range of action with a given supply of fuel, and a sacrifice of manageability in landing, arising not only from their minimum power speed being not low enough for convenience, but from their being likely to suffer loss of stability just before landing by the increase of angle of attack, necessary with the reduced speed, involving the pointing upwards of the machine as a whole, a source of instability pointed out by Prof. Bryan as an effoct of upward inclination of the propeller thrust to the line of motion, though it favours stability if the inclination be downward.

The speeds of minimum resistance and of maximum load per horsepower, otherwise that of minimum horsepower for a fixed load, both greatly depend, as Mr. 'Turnbull's figures show, on one particular thing, namely, the ratio of head resistance to drift of sup)porting planes, because it is that dependence which enables the forms of the curves in his figures to be predicted. It is probable, I think, that this ratio is a sufficiently small percentage to make it feasible to provide means, either by the ailerons or otherwise, for making, a little before landing, a large increase in the head resistance of high spoed machines and of the angle of attack, without requiring the machine to be lifted upwards, thus enabling the speed to be reduced within convenient limits. I daresay the thing is actually done in many machines, but I think it very likely that the reason is not well understood, and the thing would be better done, both as regards design and execution, if done wittingly with set purpose and understanding.

Also, the speed of minimum horsepower could, I fancy, be found for any particular machine, by a skilful pilot on a calm day. The ratio of the economical speed to it is an invariable constant, not depending on design, \&c., consequently the latter (the useful speed) would be ascertained. The outcome seems to be, as regards both Langley's and the other experiments, that it is impossible to prevent edge eddies and surface fric ion influencing the experimental values of the coefficient $\mathrm{K}$ in the formula: Pressure $=\mathrm{KAV}^{2} \sin \beta$ where $A$ is the area, $V$ the speed, and $\beta$ the angle of attack, and in other similar formulæ quite appreciably at small angles of attack. The correction for these disturbing influences can, however, be made with apparently sufficient accuracy by finding the point of minimum horsepower, and possibly the coefficient of surface friction can be separated from that belonging to edge eddies. Langley's plate was thick enough, if I remember rightly. for its square edge-it was not sharpened - to have, as he remarked, a quite appreciable effect ; but other experimenters have worked, I think, with much finer edges. I do not know what sort of edges M. Eiffel's planes had.

MAURICE F. FITZGISRALD.

P.S.-I think it is unfortunate that Mr. Turnbull did not happen to test the relation between minimum horsepower per $1000 \mathrm{lbs}$. and speeds corresponding, it being approximately linear, and this circumstance could not have escaped attention. 